\title{
Correlation between permanent teeth eruption and nutrition status of 6-7-years-old children
}

\author{
Della Lailasari*, Yuliawati Zenab*, Erna Herawati**, "Indah Suasani Wahyuni** \\ *Department of Orthodontics Faculty of Dentistry Universitas Padjadjaran, Indonesia \\ **Department of Oral Medicine Faculty of Dentistry Universitas Padjadjaran, Indonesia
}

\begin{abstract}
Introduction: Tooth eruption is influenced by various factors, one of them is nutritional factors. This study was aimed to determine the relationship between the number of permanent teeth erupted with nutritional status in 6-7-years-old children. Methods: This research was cross-sectional and correlational data analysis. The study was conducted towards as much as 57 children aged 6-7 years old. The sampling method was the purposive sampling technique conducted in Tanjungsari 2 State Elementary School, Sumedang Regency. The nutritional status was calculated based on the Body Mass Index (BMI) according to age from the anthropometric measurements of body weight and height. Assessment of nutritional status was performed using the WHO Anthroplus $®$ v1.0.4 application. Statistical analysis was performed using the Spearman correlation test and Mann-Whitney difference test. Results: The correlation test has obtained the value of $\rho=0.037$, which showed a significant relationship between the number of permanent teeth erupted with nutritional status of 6-7-years-old children. The Spearman correlation coefficient has obtained the value of $r=0.277$, thus showed the weak strength and positive direction of the correlation. Conclusion: There is a relationship between the nutritional status and the number of permanent teeth erupted in children aged 6-7 years old in the Tanjungsari Sub-district of Sumedang Regency. The higher the nutritional status of a child, the more number of permanent teeth erupted.
\end{abstract}

Keywords: 6-7-years-old children, nutritional status, permanent teeth eruption.

p-ISSN: 1979-0201; e-ISSN: 2549-6212; Available from: http://jurnal.unpad.ac.id/pjd/editor/submission/18322

DOI: http://dx.doi.org/10.24198/pjd.vol30no2.18322

Submission: November 23, 2017; Accepted: June 29, 2018; Published online: July 31, 2018

\section{INTRODUCTION}

Tooth eruption is the tooth movement in the jaw bone towards its functional position in the oral cavity. This eruption process continues until the tooth has contact with the antagonistic teeth. ${ }^{1}$ Clinically, tooth eruptions are characterised by the appearance of the crown or when the cusp penetrates the gingival part. ${ }^{2}$ The permanent tooth begins to erupt at the age of 6-7 years old, which is an eruption of mandibular first premolar, mandibular first incisors, and maxillary first molar. ${ }^{3}$

Permanent tooth eruption is a complex process influenced by various factors, such as genetics, gender, premature birth, hormones, systemic diseases, nutrition, socio-economic, and

\#Corresponding author: Indah Suasani Wahyuni, Department of Oral Medicine, Faculty of Dentistry, Universitas Padjadjaran, Indonesia

Sekeloa Selatan I, Bandung 40132, Indonesia. Phone: +62 821-1695-5033. E-mail: indah.wahyuni@fkg.unpad.ac.id 
local factors. ${ }^{4,5}$ Tooth eruption time can occur earlier or later. However, eruption delay is the most common thing. ${ }^{2}$ Delayed tooth eruption can interfere with the occlusal relationship resulting in malocclusion and cause mastication problem. $^{6}$ If the delayed tooth eruption is the anterior teeth, it will give a negative psychological influence to the child due to the aesthetical aspect. ${ }^{7}$ Delayed tooth eruption also causes delayed orthodontic treatment, because it has to wait until the tooth erupts. ${ }^{7}$

Malnutrition causes oral disease manifestations including angular cheilitis caused by iron deficiency, vitamin B12, and folic acid. ${ }^{8}$ Nutrition is food intake in relation to the human body's need for food substances. ${ }^{9}$ The concept of nutrition is adequate nutrients, both in terms of quantity, quality, and the body's ability to use it appropriately for metabolism of a healthy body. During childhood, adequate nutrition is needed for the body's biochemical activities in the growth and development. Malnutrition will make human body unable to carry out the daily activities, and will also cause growth and development problems. ${ }^{10}$

Nutritional deficiencies are able to affect the tooth development because the role of nutrition for the oral tissue is not different from other tissues of the body's organs. ${ }^{11}$ Insufficient intake of carbohydrates, proteins, fats, iodine, calcium, magnesium, phosphorus, vitamin $\mathrm{C}$, and vitamin D during the tooth growth and development period can cause delayed tooth eruption. ${ }^{2,12-17}$

Based on the Ministerial Decree of the Ministry of Health of The Republic of Indonesia no. 1995 of 2010 stated that to assess the children's nutritional status, the WHO-referred anthropometric standard was required. Assessment of the nutritional status of 6-7-yearsold children must be performed using the body mass index according to age (BMI / U) with anthropometric measurements of body weight and height. Nutritional status assessment is used to categorise the children's nutritional status as the category of very thin, thin, normal, fat, and obese. ${ }^{18}$ Anthropometric measurements are widely used to measure individual or population general nutritional status, with non-invasive technique, easy procedures, and economic. ${ }^{19,20}$

Based on the results of the 2013 Indonesian Basic Health Research (RISKESDAS) on the nutritional status, the assessment of nutritional status was divided by age, which was the nutritional status of children aged 0-5-years-old, children aged 5-12-years-old, adolescents aged 13-15-yearsold, adolescents aged 16-18-years-old, and adults aged $\geq 18$-years-old. Nationally, the prevalence of the 5-12-years-old children nutritional status was categorised as very thin in as much as $4.0 \%$, thin $7.2 \%$, normal $70 \%$, fat $10.8 \%$, and obese $8.0 \% .{ }^{21}$

The results of research conducted in West Sumatra towards children aged 6-7-years-old with the total of 412 children, obtained the results that the erupted permanent mandibular first molars were found in as much as 360 children, consisted of 149 children with thin nutritional status, 197 children with normal nutritional status, 6 children with fat nutritional status, and 8 children with nutritional status of obesity. The unerupted permanent mandibular permanent first molars were found in as much as 52 children, consisted of 38 children with thin nutritional status, and 14 children with normal nutritional status. The results showed that malnutrition could cause delays in the eruption of the mandibular permanent first molars. The study also showed that there was a significant relationship between nutritional status and eruption of the mandibular permanent first molars $(p=0.000 ; r=0.389) .{ }^{22}$

Research conducted towards children aged 5-14-years-old by the United States National Health and Nutrition Examination Survey (NHANES) in 2001-2006 showed that children with nutritional status of obesity had more erupted teeth than non-obese children during mixed tooth period. Teeth in obese children tend to erupt earlier than non-obese children, with the average of as much as 1.44 more than non-obese children. ${ }^{23}$

This research was conducted in Sumedang Regency, which is the location of Universitas Padjadjaran so that it is expected that the academic community of Universitas Padjadjaran will be able to foster and giving an academic service to the nearest area. Also, children aged 6-7-years-old are the best age stage, 
considering that at this age, there is only a few erupted permanent teeth thus makes it easier for examination. This study was aimed to obtain information regarding the relationship between the number of permanent teeth erupted with nutritional status in 6-7-years-old children.

\section{METHODS}

This research method is cross sectional and correlational data analysis. The study was conducted on children aged 6-7 years totaling 57 people in February 2017. Sampling using purposive sampling technique in SDN Tanjungsari 2 Sumedang District. Inclusion criteria were elementary school students in grade 1 at SDN Tanjungsari 2, aged 6-7 years old, willing to take part in the study, get parental / guardian approval through the signing of an informed consent form. Exclusion criteria were having cleft lip and palate abnormalities.

The number of eruptions of permanent teeth is calculated based on the number of permanent teeth that have penetrated the oral mucosa (emerge). Visual examination was carried out using the mouth glass, starting from the posterior right side of the maxilla and then anterior and posterior to the left maxilla, then the left mandibular posterior teeth then anterior and right posterior to the lower jaw.

Nutritional status is calculated based on the Body Mass Index (BMI) according to age from anthropometric measurements of body weight and height. Weight measurement using digital scales with accuracy of $0.1 \mathrm{~kg}$. Bada height measurement using stature meter with accuracy of $0.1 \mathrm{~cm}$. Assessment of nutritional status using the WHO Anthroplus v1.0.4 application. Data in the form of name, gender, weight, height, date of birth and date of examination are entered into the application to get a threshold value (Z-score). Furthermore, the child's threshold value is compared to the threshold value set by the Ministry of Health and is categorized as follows ${ }^{18}$ : $1=$ Very thin: $<-3 \mathrm{SD} ; 2$ = Skinny: $-3 \mathrm{SD}$ to $<-2 \mathrm{SD}$; $3=$ Normal: -2 SD to 1 SD; 4 = Fat: $>1$ SD to $2 \mathrm{SD}$; 5 = Obesity: > 2 SD.

Data on the number of permanent teeth that have been erupted and nutritional status were tested using the Spearman correlation test and Mann Whitney different test. Correlation test in the study aims to determine whether there is a significant relationship between the number of eruptions of permanent teeth with nutritional status in children aged 6-7 years. In this correlation test, a significant relationship was determined with a value of $\rho<0.05$. Different tests were conducted to find out whether there were significant differences in the number of eruptions of permanent teeth, as well as differences in each category of nutritional status. In this difference test, a significant difference was determined with a value of $p<0.05$.

\section{RESULTS}

The study sample consisted of 57 people consisting of 28 boys (49.1\%) and 29 children (50.9\%) (Table 1). Most children aged 6-7 years at SDN Tanjungsari 2 have a normal nutritional status of 50 people $(87.7 \%)$. Children with thin nutritional status were 2 people (3.5\%), fat nutritional status were 3 people $(5.3 \%)$, and nutritional status of obesity was 2 people (3.5\%) (Table 1). Men have an average number of eruptions of permanent teeth more than women (Table 2). The highest number of permanent teeth erupted was in the obesity nutritional status of 10.00 teeth, and the lowest average was in the normal nutritional status of 6.20 teeth (Table 2 ). In normal nutritional status there were 19 people who had less than 6 teeth, 9 people who had 6 teeth, and 22 people who had more than 6 teeth (Table 2).

In different tests it was found that there were no significant differences in the number of eruptions of permanent teeth between men and women with a value of $p=0.949$ (Table 3 ). Table 3 also showed that there is no significant difference in the number of eruptions of permanent teeth between thin nutritional status and normal with a value of $p=0.885$. Table 3 showed that there is no significant difference in the number of eruptions of permanent teeth between normal nutritional status and fat with a value of $p=0.095$. Table 3 also showed that there is no significant difference in the number of eruptions of permanent teeth between the nutritional status of obese and 
obesity with a value of $p=1.000$.

The test results of differences in the number of eruptions of permanent teeth in men and women showed insignificant results, as well as differences in the number of eruptions of permanent teeth between children with various

Table 1. Sample characteristics based on gender and nutritional status

\begin{tabular}{|c|c|c|}
\hline \multicolumn{3}{|c|}{ Gender } \\
\hline Category & Frequency & $\%$ \\
\hline Male & 28 & 49.1 \\
\hline Female & 29 & 50.9 \\
\hline Total & 57 & 100 \\
\hline \multicolumn{3}{|c|}{ Nutritional status } \\
\hline Category & Frequency & $\%$ \\
\hline Very thin & 0 & 0 \\
\hline Thin & 2 & 3.5 \\
\hline Normal / Healthy weight & 50 & 87.7 \\
\hline Fat & 3 & 5.3 \\
\hline Very fat / Obese & 2 & 3.5 \\
\hline Total & 57 & 100 \\
\hline
\end{tabular}

differences in nutritional status did not show a significant difference. But the relationship of the number of eruptions of permanent teeth of 6-7 year old children in Tanjungsari, Sumedang, with nutritional status in general has a significant difference but has a weak positive correlation.

Table 2. Average number of erupted permanent teeth based on gender, nutritional status, and healthy weight condition

\begin{tabular}{|c|c|c|c|}
\hline \multicolumn{4}{|c|}{ Gender } \\
\hline Category & Min & $\operatorname{Max}$ & Mean \\
\hline Male & 1 & 12 & 6.61 \\
\hline Female & 0 & 11 & 6.41 \\
\hline \multicolumn{4}{|c|}{ Nutritional status } \\
\hline Category & Min & $\operatorname{Max}$ & Mean \\
\hline Very thin & - & - & - \\
\hline Thin & 6 & 7 & 6,50 \\
\hline $\begin{array}{l}\text { Normal / } \\
\text { Healthy weight }\end{array}$ & 0 & 12 & 6,20 \\
\hline Fat & 6 & 12 & 9,33 \\
\hline $\begin{array}{l}\text { Very fat / } \\
\text { Obese }\end{array}$ & 10 & 10 & 10,00 \\
\hline Total & 0 & 12 & 6,51 \\
\hline \multicolumn{4}{|c|}{ Healthy weight condition } \\
\hline Tooth amount & $F$ & \multicolumn{2}{|c|}{$\%$} \\
\hline$<6$ & 19 & \multicolumn{2}{|c|}{38.0} \\
\hline 6 & 9 & \multicolumn{2}{|c|}{18.0} \\
\hline$>6$ & 22 & \multicolumn{2}{|c|}{44.0} \\
\hline Total & 50 & \multicolumn{2}{|c|}{100} \\
\hline
\end{tabular}

Table 3. Difference test results

\begin{tabular}{|c|c|c|c|}
\hline \multicolumn{4}{|c|}{ Difference test of erupted permanent tooth amount between male and female } \\
\hline Gender & Tooth amount average & P-value & Notes \\
\hline Male & 6.61 & \multirow{2}{*}{0.949} & \multirow{2}{*}{ Not significant } \\
\hline Female & 6.41 & & \\
\hline \multicolumn{4}{|c|}{ Difference test of erupted permanent tooth amount between thin and normal nutritional status } \\
\hline Nutritional status & & & Notes \\
\hline Thin - normal & & & Not significant \\
\hline \multicolumn{4}{|c|}{ Difference test of erupted permanent tooth amount between normal and fat nutritional status } \\
\hline Nutritional status & & & Notes \\
\hline Normal - fat & & & Not significant \\
\hline \multicolumn{4}{|c|}{ Difference test of erupted permanent tooth amount between fat and obese nutritional status } \\
\hline Nutritional status & & & Notes \\
\hline Fat - obese & & & Not significant \\
\hline
\end{tabular}




\begin{tabular}{|c|c|c|c|}
\hline \multicolumn{4}{|c|}{ Difference test between erupted permanent tooth amount and nutritional status of 6-7-years-old children } \\
\hline Variable & R-value & P-value & Notes \\
\hline $\begin{array}{l}\text { Relationship between } \\
\text { erupted permanent tooth } \\
\text { amount and nutritional } \\
\text { status of } 6 \text {-7-years-old } \\
\text { children }\end{array}$ & 0.277 & 0.037 & Not significant \\
\hline
\end{tabular}

\section{DISCUSSION}

The subject of this study consisted of a balanced composition or sex ratio between men and women, and most $(87.7 \%)$ had normal nutritional status (Table 1). This is consistent with the results of the 2013 Indonesian Basic Health Research (RISKESDAS) that the prevalence of nutritional status of children aged 5-12 years in Indonesia has more normal nutritional status (70\%). ${ }^{21}$ The number of normal nutritional status in this study is thought to be influenced by middle to upper socioeconomic, parental knowledge of food nutrition intake is quite good and influenced by genetics.

The results showed that the average number of eruptions of permanent teeth in males was greater than in females (Table 2). This is not as stated by Almonaitiene, et al. that permanent teeth in women erupt earlier than in men, which occurs because the onset of female maturation is earlier than men. ${ }^{4}$ Men have an average number of teeth permanent as much as 6.61 teeth, a minimum number of 1 tooth, and a maximum number of 12 teeth. Whereas women had an average number of permanent teeth as much as 6.41 teeth, a minimum number of 0 teeth, and a maximum number of 11 teeth.

However, based on the different tests results as presented in Table 3 , it is known that there is no significant difference $(\rho=0.949)$ of the number of eruptions of permanent teeth between men and women.

The age of 6-7 years is the mixed tooth period, namely the eruption of permanent teeth, namely eruption of 2 mandibular first molar teeth, 2 mandibular first incisors, and 2 upper maxillary first molars. ${ }^{3}$ overall has an average number of permanent teeth as much as 6.51 teeth, this means that the sample has an average number of teeth greater than the theory that is as many as 6 teeth. It is estimated that this happens because there is a possibility of eruption of permanent teeth for the first time in these children occurs earlier, so that at that age the number of teeth that have erupted more than normal. This is in accordance with Suri's statement, et al., That eruption time can occur faster than normal eruption time. ${ }^{2}$

The average number of permanent teeth that have been erupted in skin nutritional status was 6.50 teeth, normal nutritional status was 6.20 teeth, fat nutritional status was 9.33 teeth, and obesity nutritional status was 10.00 teeth (Table 2). Obese nutritional status has the highest number of teeth, which is 10.00 teeth, and the minimum number of teeth is 10 teeth, the maximum number is 10 teeth. This is consistent with the research of Must, et al, that obese children have an average number of teeth more than non-obese children during the mixed tooth period. Obesity affects the time of tooth eruption due to acceleration of growth and maturation. In their study, teeth in obese children erupted earlier than non-obese children with an average of 1.44 more teeth erupted than non-obese children. ${ }^{23}$ Almonaitiene, et al., revealed that there was a positive relationship between weight, height, and tooth eruption. Obese children experience tooth eruption 1.2 to 1.5 years earlier than children with normal Body Mass Index (BMI).

The second highest number of eruptions was found in the fat nutritional status of 9.33 teeth, with a minimum number of teeth of 6 teeth, and a maximum number of 12 teeth (Table 4). In Hilgers' research, et al, it was stated that children with nutritional status of obese and obese accelerated the development of teeth compared to normal nutritional status. ${ }^{24}$ The average number of eruptions was the third highest in the skin nutritional status of 6.50 teeth, with 
the number minimum teeth of 6 teeth, and a maximum number of 7 teeth. The lowest average is in the normal nutritional status of 6.20 teeth, with a minimum number of teeth of 0 teeth and a maximum number of 12 teeth. In this study, it can be said that the average number of eruptions of permanent teeth in normal nutritional status was less than in thin nutritional status.

In this study a different test was conducted to find out whether there were significant differences or not between the number of eruptions of permanent teeth with each category of nutritional status. This test is divided into three, namely the test of the difference in the number of eruptions of permanent teeth in thin nutritional status with normal, normal with fat, and fat with obesity. The results showed that there were no significant differences in the number of eruptions of permanent teeth between thin and normal nutritional status with a value of $p=0.885$ (Table 3), there was no significant difference in the number of eruptions of permanent teeth between normal nutritional status and fat with a value of $p=0.095$ (Table 3), and there was no significant difference in the number of eruptions of permanent teeth between the nutritional status of obese and obese with the value of $p=$ 1.000 (Table 3).

The results of the analysis using Spearman correlation analysis showed that there was a significant relationship between the number of eruptions of permanent teeth with nutritional status in children aged 6-7 years at SDN Tanjungsari 2 with a value of $p=0.037$. The correlation relationship is weak and has a positive correlation direction with the correlation coefficient $r=0.277$ (Table 3). Direction of positive correlation means that the relationship that occurs is unidirectional, the greater the value of one variable, the greater the value of other variables. In this study means that if the nutritional status is higher then the number of permanent teeth that have erupted is increasing. This can be seen in the nutritional status of fat which has an average number of teeth 9.33 teeth and obesity with an average number of teeth 10.00 teeth. However, the average number of teeth in normal nutritional status (6.20 teeth) was less than thin nutritional status (6.50 teeth), this could be due to the data of the research sample was not normally distributed. In this study, only nutritional factors were used as research variables, while other factors were not included. The relationship has a weak correlation due to suspected genetic factors and hormonal factors that have a large influence on tooth eruption.

Correlation test results in this study are in accordance with the results of other studies regarding the relationship of nutritional status with tooth eruption. In Alhamda's research in Lintah Buo Subdistrict, Tanah Datar Regency, Indonesia, the relationship between nutritional status and eruption of mandibular permanent first molars was found to have a significant relationship with a value of $p=0,000$, and a weak correlation and direction of positive correlation with $r=$ $0.389 .{ }^{22}$ Research conducted by Rahmawati, et al., regarding the relationship between nutritional status and eruption status of mandibular permanent central incisors obtained a significant relationship with the value $p=0.038 .{ }^{25}$

Based on the research of Psoter et al. in 2008 on the impact of energy-protein malnutrition on Haitian adolescents, it was found that energyprotein malnutrition caused delays in eruption of permanent teeth. ${ }^{13}$ The results of this study were later explained by Weltzien et al in 2013 that protein-energy malnutrition can cause the occurrence of delays in tooth eruption as a result of abnormal metabolic processes. Energyprotein malnutrition is a lack of protein, energy from food, or both, relative to body needs. ${ }^{11}$ Metabolism requires the intake of carbohydrates, proteins and fats. ${ }^{12}$ lodine is used to produce thyroxine hormone which regulates metabolic rate, iodine deficiency causes delays in tooth eruption. ${ }^{12}$ Growth and development of teeth are also affected by vitamin A, vitamin C, vitamin D, calcium, phosphorus, iodine and magnesium. ${ }^{12,14}$ Nutritional conditions of children are influenced by direct factors such as food consumption and indirect factors such as economic factors related to the problem. work and income of a family and knowledge factors related to the selection and provision of nutritious and diverse foods. ${ }^{26}$ 


\section{CONCLUSION}

There is a relationship between the nutritional status and the number of permanent teeth erupted in children aged 6-7 years old in the Tanjungsari Sub-district of Sumedang Regency. The higher the nutritional status of a child, the more number of permanent teeth erupted.

\section{ACKNOWLEDGEMENT}

The author would like to thank DRPMI Universitas Padjadjaran for funding support for this research through the 2016 lecturer research capacity development (HPKRD) grant scheme.

\section{REFERENCES}

1. Koch G, Poulsen S. Pediatric in Dentistry: A Clinical Approach. $1^{\text {st }}$ ed. Copenhagen: Munksgaard; 2001. p. 302-3.

2. Suri L, Gagari E, Vastardis H. Delayed Tooth Eruption: Pathogenesis, Diagnosis, and Treatment: A Literature Review. Am J Orthod Dentofacial Orthop. 2004; 126(4): 432-45. DOI: $10.1016 / 5088954060400530 \mathrm{X}$

3. Dean J, McDonald R, Avery D. McDonald and Avery Dentistry for the Child and Adolescent. 9th ed. St. Louis: Mosby-Elsevier; 2010. p. 42; 151-152.

4. Almonaitiene R, Balciuniene I, Tutkuviene J. Factors Influencing Permanent Teeth Eruption. Part One-- General Factors. Stomatologija. 2010; 12(3): 67-72.

5. Peedikayil FC. Delayed Tooth Eruption. E-Journal of Dentistry. 2011; 1(4): 81-6.

6. Arathi R, Suprabha BS, Pai SM. Permanent Molars: Delayed Development and Eruption. J Indian Soc Pedod Prev Dent. 2006; 24 Suppl 1: S15-7.

7. Park JH, Tai K, lida S. Unilateral Delayed Eruption of a Mandibular Permanent Canine and The Maxillary First and Second Molars, and Agenesis of The Maxillary Third Molar. Am J Orthod Dentofacial Orthop. 2013; 143(1): 134-9. DOI: $10.1016 /$ j.ajodo.2011.11.024

8. Greenberg MS, Glick M, Ship JA. Burket's Oral Medicine. 11th ed. North Carolina: PMPH USA; 2008.
9. World Health Organization [homepage on internet]. Geneva: 2016. Nutrition. [cited 2016 Oct]; [about 3 screens]. Available from: http://www.who.int/topics/nutrition/en/

10. Adegun JA, Ajayi-Vincent OB, Alebiosu EO. Differences in The Nutritional Status of Young School Children from Public and Private Owned Primary Schools in Ekiti State, Nigeria. Eur Sci J. 2013; 9(7): 32-7.

11. Heinrich-Weltzien R, Zorn C, Monse B, Kromeyer-Hauschild. Relationship between Malnutrition and The Number of Permanent Teeth in Filipino 10 to 13 Years Olds. BioMed Res Int. 2013; 2013: 1-8. DOI: 10.1155/2013/205950

12. Stegeman C, Davis J. The Dental Hygienist's Guide to Nutritional. 4th ed. Philadelphia: Saunders; 2014. pp. 4, 234-5, 248.

13. Psoter W, Gebrian B, Prophete S, Reid B, Katz R. Effect of Early Childhood Malnutrition on Tooth Eruption in Haitian adolescents. Community Dent Oral Epidemiol. 2008; 36(2): 179-89. DOI: $10.1111 / j .1600-0528.2007 .00386 . x$

14. Sheetal A, Hiremath VK, Patil AG, Sajjansetty S, Kumar SR. Malnutrition and Its Oral Outcome - A Review. J Clin Diagn Res. 2013; 7(1): 17880. DOI: $10.7860 /$ JCDR/2012/5104.2702

15. Galhotra V, Ahluwalia P, Jodhka S, Sethi S, Gambhir RS. Effect of nutritional rickets on dental development in North Indian children: A prospective study. J Ped Dent. 2015; 3(3): 88-91. DOI: 10.4103/2321-6646.164879

16. Ige AO, Adewoye EO. Oral Magnesium Treatment Reduces Anemia and Levels of Inflammatory Markers in Experimental Diabetes. J Diet Suppl. 2016: 1-13. DOI: 10.1080/19390211.2016.1205700

17. Rakhmayantie N, Herawati E, Herawati DHD. Effect of nutritional intake towards Angular cheilitis of orphanage children. Padjadjaran J Dent. 2016; 28(3): 164-70. DOI: 10.24198/pjd. vol28no3.13674

18. Ministerial Decree of the Ministry of Health of The Republic of Indonesia no. 1995 of 2010. Anthropometric Standards Assessment of Children's Nutritional Status. Jakarta: Ministry of Health of the Republic of Indonesia; 2010.

19. Knox TA, Zafonte-Sanders M, Fields-Gardner C, Moen K, Johansen D, Paton N. Assessment 
of Nutritional Status, Body Composition, and Human Immunodeficiency Virus-Associated Morphologic Changes. Clin Infect Dis. 2003; 36Suppl2: S63-S68. DOI: 10.1086/367560

20. Elkholy TA, Hassanen NHM, Rasha. Demographic, Socio-Economic Factors and Physical Activity Affecting the Nutritional Status of Young Children Under Five Years. Life Sci J. 2012; 9(4): 3604-14.

21. National Institute of Health Research and Development (NIHRD). Indonesia Basic Health Research (RISKESDAS) 2012-2013. Jakarta: Ministry of Health of the Republic of Indonesia; 2013.

22. Alhamda S. Relationship Between Nutritional Status and Eruption of First Permanent Mandibular Molar Teeth Among The School
Children in Indonesia. South East Asia J Public Health. 2(2): 85-6. DOI: 10.3329/seajph. v2i2.15962

23. Must A, Phillips SM, Tybor DJ, Lividini K, Hayes $C$. The association between childhood obesity and tooth eruption. Obesity (Silver Spring). 2012 Oct; 20(10): 2070-4. DOI: 10.1038/ oby. 2012.23

24. Hilgers KK, Akridge M, Scheetz JP, Kinane DF. Childhood Obesity and Dental Development. Ped Dent; 2006: 28(1).

25. Rahmawati AD, Retriasih H, Medawati A. The Relationship between Nutritional Status and the Status of the Eruption of Permanent mandibular central incisors. IDJ. 2014; 3(1): 16-21.

26. Wong HM, Peng SM, Yang Y, King NM, McGrath CPJ. Tooth eruption and obesity in 12-year-old children. J Dent Sci. 2007; 12(2): 126-32. DOI: 10.1016/j.jds.2016.10.004 